\title{
WHAT IF ELECTRICAL STIMULATION COULD TREAT PHANTOM LIMB PAIN?
}

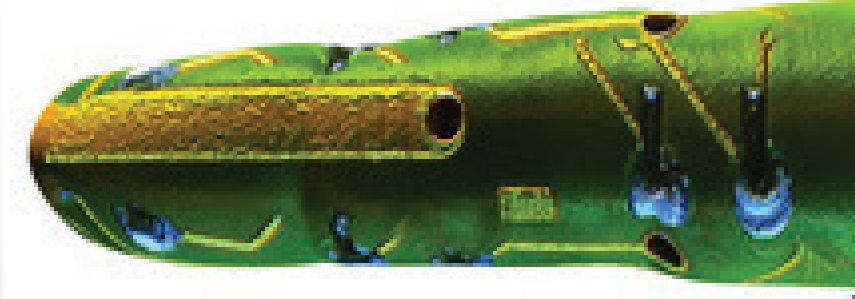

\author{
MOST PEOPLE WHO HAVE HAD A LIMB AMPUTATED \\ WILL EXPERIENCE SOME FORM OF PHANTOM LIMB \\ PAIN. UNFORTUNATELY, CURRENTLY AVAILABLE \\ DRUG TREATMENTS HAVE VARYING SUCCESS. \\ DR KATHARINE POLASEK, AT HOPE COLLEGE \\ IN THE US, IS INVESTIGATING WAYS TO USE \\ ELECTRICAL STIMULATION TO TREAT THIS PAINFUL \\ PHENOMENON
}

\section{TALK LIKE A NEURAL ENGINEER}

AMPUTATION - the surgical removal of part of the body, such as an arm or leg

CENTRAL NERVOUS SYSTEM - consisting of the brain and spinal cord

EEG - abbreviation of electroencephalogram, which is a recording of brain activity using a special machine. Small sensors are attached to the scalp to pick up the electrical signals produced when brain cells send messages to each other

ELECTRODE - a small piece of metal or other substance that is used to take an electric current to or from a source of power, a piece of equipment, or a living body

NEUROPLASTICITY - the ability of the brain to form and re-organise synaptic connections, especially in response to learning, experiences or following injury
PERIPHERAL NERVOUS SYSTEM - consisting mainly of nerves, which are enclosed bundles of fibres connecting the central nervous system to every part of the body

REFERRED SENSATIONS - sensations felt in parts of the body far away from the site receiving the electrical stimulation

SOMATOSENSORY SYSTEM - the part of the sensory system concerned with the perception of sensations such as touch, pain, pressure and vibration

SURFACE ELECTRICAL STIMULATION (SES) - a non-invasive method of electrical stimulation which involves placing electrodes on the skin
Imagine losing your left arm, but months later you experience pain in your left hand, even though it is no longer there. This is known as phantom limb pain, the painful sensations amputees feel in their missing limbs. Even though the word 'phantom' might suggest otherwise, phantom limb pain is a very real and painful phenomenon, often described as throbbing, burning or stabbing in the part of the body that has been removed. It usually starts soon after the amputation surgery, and its duration and intensity vary from person to person.

Phantom limb pain is estimated to affect up to 80 percent of amputees and can be a long- term problem, so it is essential to find ways of managing and treating the pain. Unfortunately, finding a treatment to relieve phantom limb pain can be difficult, and there are no medications that are specifically aimed at this condition.

Dr Katharine (Katie) Polasek is an associate professor of engineering at Hope College in the US. Katie and her team are using their engineering skills to find innovative ways to relieve phantom limb pain.

WHAT CAUSES PHANTOM LIMB PAIN? Scientists are still not certain about the exact mechanisms behind phantom limb pain, despite extensive research into the topic. It is most likely due to the brain and spinal cord continuing to send signals down to the nerves of the missing limb. However, no neural signals return and so the brain gets confused. It could be that the pathway (nerve to spinal cord to brain) that used to connect to the missing limb sends signals randomly, which causes confusion in the brain that is interpreted as pain.

"Some people have shown changes in their brain after an amputation where the area of the brain that used to connect to the amputated limb now responds to another nearby body location. For example, if you 


\section{ABOUT NEURAL ENGINEERING}

Did you know that fully functional bionic arms that respond to signals from the brain have been developed for amputees? The user only has to think about moving their hand, and signals from the brain will be detected by electrodes in the bionic arm, causing it to move! This life-changing invention is all due to the work of neural engineers.

Neural engineering is a discipline within biomedical engineering. It focuses on using engineering techniques and skills to understand, interface with and manipulate the nervous system. Neural engineers are interested in understanding how the brain functions, and often create computer models of neural systems to better

understand them and how they interact.

WHY DO WE NEED NEURAL

ENGINEERS?

Neural engineers are essential for many medical-related technologies and therapies. They might design heart devices such as pacemakers or defibrillators, or develop brain devices to help people with Parkinson's disease or epilepsy, or work on therapies to help people who have suffered from a stroke or spinal cord injury.

\section{DOES KATIE RECOMMEND \\ A CAREER IN NEURAL \\ ENGINEERING?}

"Neural engineering is a pretty narrow field, but I love learning about how the different parts of the body communicate and work together to allow us to do all of the amazing things that we can do," she says. "As a neural engineer, I have to understand what the body is doing so that I can use my engineering skills to restore function that has been lost, or take pain away."

\section{EXPLORE A CAREER IN NEURAL ENGINEERING}

- You can read more about neural engineering on the IEEE Engineering in Medicine \& Biology Society website: www.embs.org/about-biomedical-engineering/ our-areas-of-research/neural-engineering/

- The Royal Academy of Engineering also has a handy guide: www.raeng.org.uk/publications/reports/neuralengineering-briefing

- Neural engineering is a specialised field, so it is useful to read up on the more general field of biomedical engineering. UCAS provides a great summary: www.ucas. com/ucas/after-gcses/find-career-ideas/explore-jobs/ job-profile/biomedical-engineer

- Practical experience is a good way to find out whether neural engineering, biomedical engineering or engineering in general is the career for you. Hope College hosts ExploreHope which, as Katie says, "runs awesome engineering camps for older kids." Research the engineering departments of universities near you to see if they hold similar camps or outreach activities for schools and students.

- Katie recommends finding a neural engineer and shadowing them, if possible. "Once you get to engineering school, apply for an internship or research experience so that you can start doing real science and/or engineering," she says. "The best way to know if you like something is to try it out!"

- According to Indeed, the average salary for a neural engineer in the US ranges from $\$ 91,000$ - $\$ 150,000$, though this will vary depending on your qualifications and whether you work for a company or at a university.

\section{PATHWAY FROM SCHOOL TO NEURAL ENGINEERING}

Maths is essential for all forms of engineering. In addition, Katie suggests learning electrical engineering concepts and computer programming. Katie took other science courses about the human body and her favourites were in anatomy and physiology.

\section{KATIE'S TOP TIPS}

01 Don't expect getting into a specific career to be a straight path, and don't worry if you're not sure what you want to do.

02 At each stage in your career, make the best decision for you at that time. It's good to have a long-term plan but life often doesn't work out exactly as you planned!

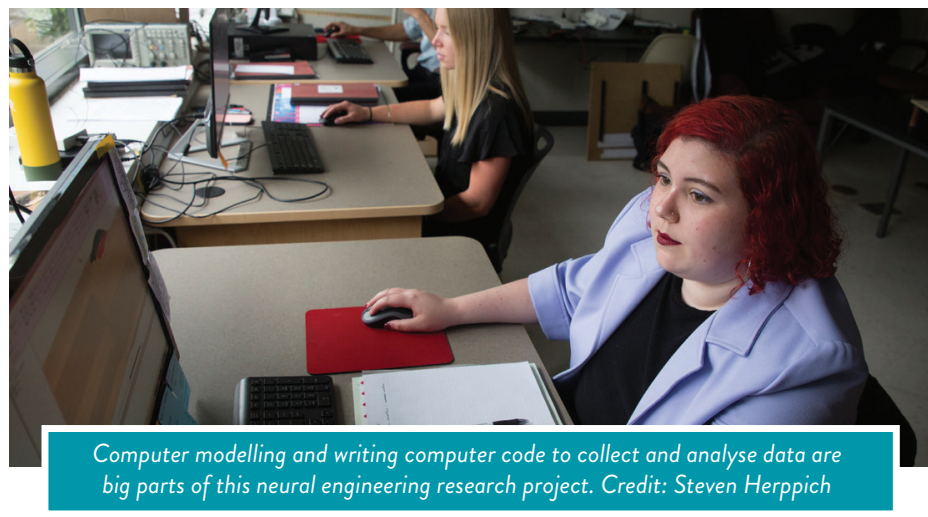




\section{HOW DID KATIE BECOME A NEURAL ENGINEER?}

WHAT WERE YOUR INTERESTS WHEN YOU WERE YOUNGER?

As a child, I always loved to let my imagination take over, using toys and dolls to create new worlds, and I have many happy memories of playing with siblings and friends that way. I loved reading fantasy books, especially those of Madeline L'Engle. As I grew older, I enjoyed playing piano and trombone, and running track and cross-country. I've also loved jigsaw puzzles all of my life.

\section{DID YOU ALWAYS KNOW YOU} WANTED TO BE AN ENGINEER?

My father is a civil engineer, so I was exposed to engineering at a young age. I didn't really have an interest in designing bridges or cars, so I didn't plan on becoming an engineer initially. When I was four, I wanted to be a monkey doctor. This progressed to baby doctor, then veterinarian, so I guess I was mostly focused on the medical field. It was in my junior year at high school that I first heard about biomedical engineering, and it sounded perfect for someone like me who was definitely interested in how the body worked but also liked math and solving problems.

YOU HAVE A BSE IN MECHANICAL ENGINEERING AND A PHD IN BIOMEDICAL ENGINEERING. WHY DOES BIOMEDICAL ENGINEERING FASCINATE YOU?

When I was in high school, I remember being fascinated with how muscles produced movement. My favourite muscle was the zygomaticus major - the smiling muscle! In my anatomy and physiology class, I learned the secrets to how muscles contract and create complex movements. Once I started studying engineering, I wanted to learn more.

\section{HOW WOULD YOU DESCRIBE \\ YOURSELF?}

I like to solve problems and am very practical and hands-on. I have trouble visualising things that people tell me verbally, so I like to see the problem or draw it, based on a description. Seeing the problem helps me to find a solution.

WHAT DO YOU ENJOY OUTSIDE OF RESEARCH?

I love my work but I also love coming home at the end of the day to my husband Greg and my three boys, Isaac, Teddy and Sam. We also have two dogs and two cats who are always available for pets and snuggles. For my hobbies, I still keep up with running and playing the trombone but I added hockey as an interest when I was in graduate school. Hockey is fun and social, and a great way to exhaust myself and be part of a team. 